\title{
Neurotrauma in Old Aged: A Study from India
}

\author{
Ashok Munivenkatappa ${ }^{1} \quad$ Vineet Kumar $^{2}$ Prashant Bhandarkar ${ }^{3} \quad$ Nobhojit Roy $^{4}$ Jyoti Kamble ${ }^{5}$ \\ Amit Agrawal 6 \\ 1 VRDL Project, National Institute of Epidemiology, ICMR, Chennai, \\ Tamil Nadu, India \\ 2 Department of Surgery, Lokmanya Tilak Municipal Medical College \\ and General Hospital, Mumbai, India \\ ${ }^{3}$ Department of Statistics, Bhabha Atomic Research Centre, Mumbai, \\ India \\ ${ }^{4}$ Department of Surgery, Bhabha Atomic Research Centre, Mumbai, \\ India \\ 5 TITCO Project, Tata Institute of Social Sciences, Mumbai, India \\ ${ }^{6}$ Department of Neurosurgery, Narayana Medical College Hospital, \\ Chinthareddypalem, Nellore, Andhra Pradesh, India \\ Address for correspondence Amit Agrawal, MCh, Department of \\ Neurosurgery, Narayana Medical College Hospital, \\ Chinthareddypalem, Nellore-524003, Andhra Pradesh, India \\ (e-mail: dramitagrawal@gmail.com; dramit_in@yahoo.com). \\ Indian J Neurosurg 2017;6:4-9.
}

\begin{abstract}
Keywords

- old aged

- neurotrauma

- India

- severity

- mortality

- traumatic brain injury

- women

Introduction Traumatic brain injury (TBI) is common in all the age groups. In India with increased life expectancy and more active old-aged population, basic details of neurotrauma in old aged are limited. The aim of the present study is to determine injury pattern and factors influencing outcome of the neurotrauma in old-aged patients, and also to contribute to national trauma data.

Methods The study is based on prospective observational registry Towards Improved Trauma Care Outcomes (TITCO) database collected from four Indian government hospitals during October 1, 2013 to September 30, 2015. Data of neurotrauma patients aged 60 years or older were considered for analysis. SPSS version 24.0 was used for statistical analysis. The chi-square test was used for comparison of categorical data with significance level of $p<0.05$.

Results Old-aged patients contributed for 1,629 (10.2\%) of total neurotrauma data. Men were 2.4 times higher than women, but mortality was almost same in both the sexes. Approximately 860 (53\%) of injuries were due to falls and $490(30 \%)$ due to road traffic accidents (RTA). Approximately $708(44 \%)$ of subjects patients had moderate to severe brain injuries. Approximately 1,136 (70\%) of patients required CT scan and 435 (27\%) of patients underwent brain surgery. Approximately $588(36 \%)$ of patients expired during study period. There was significant $(p=0.0001)$ difference between mortality of old-aged and productive age group (19-59 years). The deaths between the two groups differed significantly $(p=0.0001)$ among sex, injury cause, severity, requirement of $\mathrm{CT}$ scan, and surgery.

Conclusion Our study highlights that geriatric TBI is a significant phenomenon and reflects our national data. Possible risk factors associated with deaths are identified in our population. More research is needed to develop specific management and preventive protocols.
\end{abstract}

received

August 26, 2016

accepted

October 18, 2016

published online

February 10, 2017
DOI http://dx.doi.org/

10.1055/s-0037-1598092.

ISSN 2277-954X. (c) 2016 Neurological Surgeons' Society of India
License terms

(๑) $\Theta \circledast$ 


\section{Introduction}

Aged population is rapidly growing in both developed and developing countries. ${ }^{1-3}$ In India drastic improvements in public health and medical advance in the prevention of many diseases has led to increase in percentages of aged population. The size of old-aged population has risen from 12.1 million (5\%) in 1901 to 77 million $(7.4 \%)$ in $2001 .^{2}$ As per National Commission on Population 2011, the senior citizen accounts for $8.3 \%$ of total population. ${ }^{3}$ Based on the reports from the United Nations Population Fund and Help Age International, the number of old-aged population will shoot up to $360 \%$ that is expected to increase to 323 million, constituting $20 \%$ of total population by $2050 .{ }^{3}$ Indian has already tagged under aging nations as per 2011 census. Aging is chronic issue and it will become more severe in next decades. Old aged are more vulnerable to communicable diseases (CD) as well as noncommunicable diseases (NCD). Trauma threats in last few decades of life have made them dependants in all respects, physical, financially, etc.

The growth of aged population has become an increasing problem and presents a challenge to the present health care system. In fact, neurotrauma is one of the leading causes of neurologic disability in our country. ${ }^{4}$ Age is one of the most significant factors in prediction of outcome after head injury. ${ }^{5-10}$ Increasing age with decreased physiologic reserve, diminished metabolic, and hormonal response are well-recognized risk factors for poorer outcomes after head injury. ${ }^{5,6}$ Despite increased and adverse outcomes among brain injuries in old aged, very little epidemiologic information is available from our country. In the present study, we aim to describe the pattern of injuries and factors that determine outcome among neurotrauma patients older than 60 years.

\section{Methods}

Towards Improved Trauma Care Outcome (TITCO) is prospective observational trauma database collected from four Indian government hospital was considered in this study. TITCO data was collected for the period from October 1, 2013 to September 30, 2015. Patient details of trauma cases were recorded by trained data collectors at each pre-identified centers. For the present study, data of trauma patients aged 60 years or older were considered. In India old-aged or senior citizen means any person who has attained 60 years or above as per National Policy on Older Persons, 1999, and also as per Maintenance and Welfare of Parents and Senior Citizens Act, 2007. ${ }^{2,3}$ The demographic characteristics, trauma mechanisms, trauma severity scores, and outcome were analyzed. Patients in productive age group between 19 and 59 years are compared with old-aged age group.

\section{Statistical Analysis}

Statistical computations were performed using SPSS version 24.0 (SPSS Inc., Chicago, IL, United States) for Windows and Microsoft Excel version 16. Descriptive statistics was used to report the percentages, proportions, and frequencies of demographic and outcome variables. The chi-square test was used for comparisons of the means and to test for diagonal table analysis. $p$ Values $<0.05$ were considered significant.

\section{Results}

The number of trauma patients' data collected during study period was 16,047 . A total of 1,629 (10.2\%) of these were aged 60 years or older. Mean age was $68.2 \pm 7.6$ years $(60-$ 97 years). Approximately 1,150 were (71\%) men and 479 were $(29 \%)$ women. Falls was most common cause of head injury accounting for 860 (53\%), followed by road traffic

Table 1 Demographic, severity, and investigation details of old-aged TBI patients

\begin{tabular}{|c|c|}
\hline Variables & Total $n(\%)$ \\
\hline \multicolumn{2}{|l|}{ Sex } \\
\hline Male & $1,150(71)$ \\
\hline Female & $479(29)$ \\
\hline \multicolumn{2}{|l|}{ Injury mechanism } \\
\hline Assault & $52(3.5)$ \\
\hline Burns & $70(4.5)$ \\
\hline Falls & $860(53)$ \\
\hline Railway & $41(2.5)$ \\
\hline RTA & $490(30)$ \\
\hline Pedestrian & $61(3.5)$ \\
\hline Others & $49(3)$ \\
\hline \multicolumn{2}{|l|}{ Transport mode } \\
\hline Ambulance & $1,226(75)$ \\
\hline Carried by man & $3(0.2)$ \\
\hline Police & $77(4.8)$ \\
\hline Private car & $130(8)$ \\
\hline Auto & $167(10)$ \\
\hline Not available & $26(2)$ \\
\hline \multicolumn{2}{|c|}{ Glasgow coma scale ${ }^{a}$} \\
\hline Mild & $921(56)$ \\
\hline Moderate & $259(16)$ \\
\hline Severe & $449(28)$ \\
\hline \multicolumn{2}{|c|}{ Computed tomography scan } \\
\hline Done & $1,136(70)$ \\
\hline Not done & $493(30)$ \\
\hline \multicolumn{2}{|l|}{ Brain surgery } \\
\hline Done & $435(27)$ \\
\hline Not done & $1194(73)$ \\
\hline Deaths & $588(36)$ \\
\hline
\end{tabular}

Abbreviations: RTA, road traffic injuries; TBI, traumatic brain injury. ${ }^{a}$ Data not available for $216(13 \%)$ patients. 
accident (RTA) 490 (30\%). Approximately 1,226 (75\%) of patients were bought by ambulance. Mean Glasgow coma scale (GCS) was 11.01. There was statistically significant ( $p=<0.0001$ ) difference between GCS of dead and survived old aged with an average of 7.94 and 12.68 , respectively. About two-third 1,136 (70\%) of patients underwent computed tomographic (CT) scan. Approximately 435 (27\%) of patients underwent emergency surgery for blood evacuation. For details refer -Table 1.

Approximately 588 (36\%) of old-aged patients expired. In 8th (men 37 vs. women 46\%) and 10th (men 33 vs. women $43 \%$ ) decades, frequency of women deaths is more than that of men (-Fig. 1). Adverse physiologic findings were present in 105 (6\%) for systolic blood pressure (< $90 \mathrm{~mm} \mathrm{Hg}$ ), 261 (16\%) for tachycardia ( $>100$ beats/min), 140 (9\%) for lesser hemoglobin level ( $<10 \mathrm{mg} / \mathrm{dL}), 19(1 \%)$ for tachypnea ( $>20$ cycles/min), and 16 (1\%) for lesser blood glucose level $(<70$ $\mathrm{mg} / \mathrm{dL}$ ). - Fig. 2A, B shows outcome details (alive or death) during various days and months, respectively. The outcome in different days of a week and months of a year is not statistically significant.

From the same TITCO data, we analyzed 19 to 59 years (productive age group) of age group that accounted for $10,621 / 16,047$ (66\%). Mean age was $48.8 \pm 4.7$ (18-59 years). There was statistically significant difference between the mortality of old aged and productive age group. Also, the deaths among sex (male and female), injury cause (RTA and fall], GCS (moderate and severe), requirement of CT scan, and surgery differed significantly between the two groups. See - Table 2 for details.

\section{Discussion}

TBIs in old aged vary from countries to countries. A study from Bursa city reported 3.9\%, ${ }^{11}$ China reported $19.1 \%{ }^{12}$ and data from 15 states of the United States reported 155.9 per 100,000 populations. ${ }^{13}$ A single institutional study from our country reported that $8.8 \%$ of TBI patients belong to old-aged age group. ${ }^{14}$ The percentages of TBI in old aged reported by various studies are specific to cause of injury such as falls, pedestrian, etc. The present study reports $10.2 \%$ of TBIs in old aged due to any mode of injuries. In our country, old aged people account for $8.3 \%$ of total population and $10 \%$ of total TBIs. The rapid growth of old-aged population and their TBIs caution the Indian health care system for better strengthening and improving or else its consequences are likely to take it by surprise.

To our knowledge, the present study analysis is the largest report of geriatric TBI population from our country. Our results report that men are 2.4 times more affected than women, but the death rates are almost equal in both sexes. Interestingly in 8th and 10th decades, percentage of women deaths is greater than that of men (-Fig. 1). An epidemiologic study from our country reported that female TBIs have significantly higher number of severities and deaths as compared with male TBIs, especially in oldaged age group. ${ }^{15} \mathrm{~A}$ prospective study from Scotland reported that $\mathrm{TBI}$-induced death at 1-year follow-up among females (13.5\%) was more than males (8.5\%). ${ }^{16}$ With increasing age, women are more prone to adverse outcome, though their total population is less than men.

Falls are the most common mechanism of brain injury in old-aged population followed by RTAs. ${ }^{9,17}$ In developed countries such as the United States and United Arab Emirates, the falls are leading cause of TBI among old-aged patients, accounting for 51 and 55\%, respectively. ${ }^{9,17}$ RTAs are the second most common mechanism of brain injuries accounting for $9 \%$ in the United States ${ }^{9}$ and $32 \%$ in United Arab Emirates. ${ }^{17}$ Our study results are consistent with findings from developed country where falls are major cause (53\%) followed by RTAs (30\%). However, deaths are more among RTAs (41\%) than falls (30\%), in our study. The injuries due to RTA will be much more severe than falls. The old-aged patients are more susceptible for RTAs because of associated medical conditions before injury and decreased body functioning as an aging process. ${ }^{9,13}$

Our study analysis reports almost same percentage of old-aged patients (70\%) and productive age group (72\%)

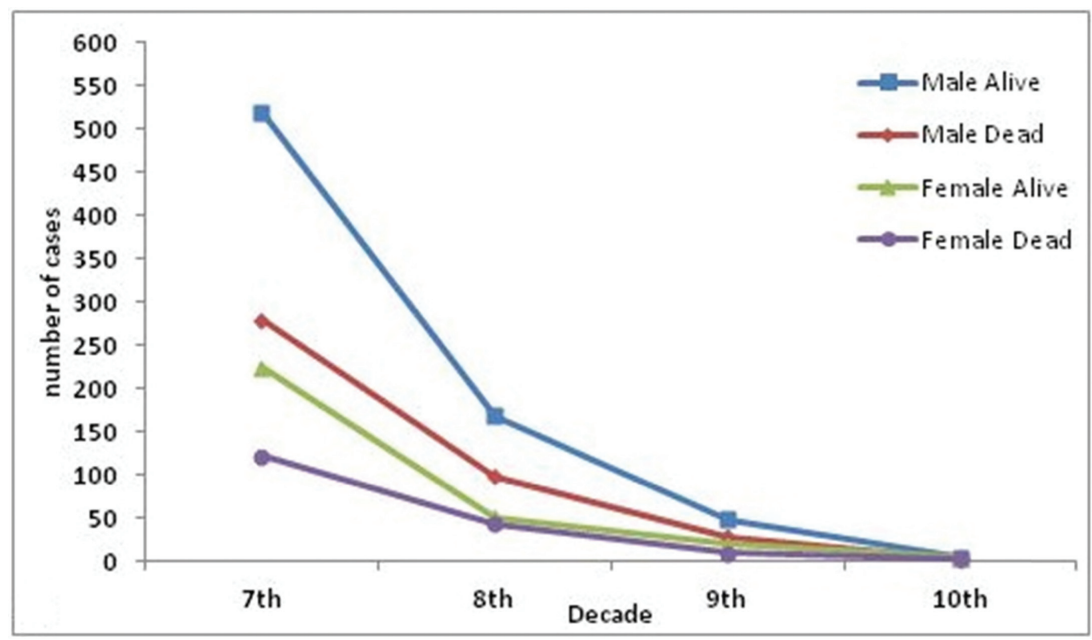

Fig. 1 Distribution of outcome among men and women in different age groups. 
Neurotrauma in Old Aged: A Study from India Munivenkatappa et al. 7

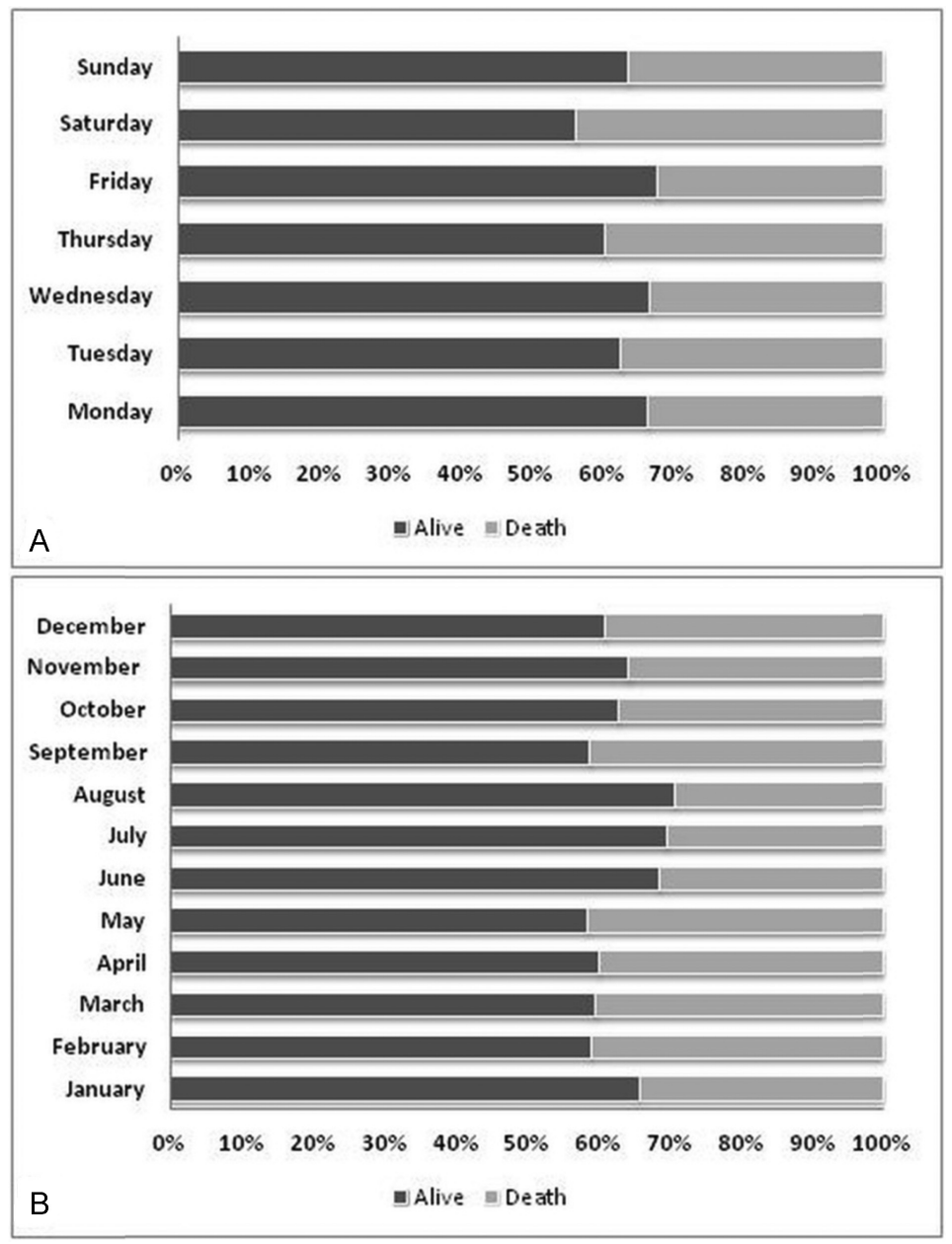

Fig. 2 Percentages of outcome (alive or death) during various days of a week (A) and months of a year (B).

Table 2 Comparison of death rates among older ( $\geq 60$ years) versus productive age groups (19-59 years) among different variables of TBI patients

\begin{tabular}{|c|c|c|c|}
\hline & $\begin{array}{l}\text { Older age group } \\
n(\%)\end{array}$ & $\begin{array}{l}\text { Productive age group } \\
n(\%)\end{array}$ & $p$ Value \\
\hline Total deaths & $588 / 1,629(36)$ & $2,534 / 10,621(24)$ & 0.0001 \\
\hline \multicolumn{4}{|l|}{ Sex } \\
\hline Male & $409 / 1,150(36)$ & $1,955 / 77,548(25)$ & 0.0001 \\
\hline Female & $179 / 479(37)$ & $552 / 1,917(29)$ & 0.02 \\
\hline \multicolumn{4}{|l|}{ Injury cause } \\
\hline RTA & $200 / 490(41)$ & $1,320 / 4,350(30)$ & 0.0001 \\
\hline Falls & $262 / 860(30)$ & $552 / 2,429(23)$ & 0.0001 \\
\hline \multicolumn{4}{|c|}{ Glasgow coma scale } \\
\hline Mild & $108 / 921(12)$ & $575 / 5,695(10)$ & 0.14 \\
\hline Moderate & $74 / 259$ (29) & $253 / 1,284(20)$ & 0.0002 \\
\hline Severe & $306 / 449(68)$ & $1,372 / 2,448(56)$ & 0.0001 \\
\hline \multicolumn{4}{|c|}{ Computed tomography scan } \\
\hline Done & $379 / 1,136(33)$ & $1,446 / 7,654(19)$ & 0.0001 \\
\hline \multicolumn{4}{|l|}{ Brain surgery } \\
\hline Done & $136 / 435(31)$ & $613 / 2,583(24)$ & 0.001 \\
\hline
\end{tabular}

Abbreviations: RTA, road traffic accident; TBI, traumatic brain injury. 
require CT scan for any abnormal brain findings as consequence of injury. However, the deaths are almost twice among old aged as compared with productive age group who have undergone CT scan (old-aged: 33\%, productive age: $19 \%, p=0.0001$ ). Studies have reported that old-aged patients require CT scan in approximately 77 to $83 \%$ of total TBIs. ${ }^{14,18}$ Our study reports that $27 \%$ of oldaged patients required surgery for evacuation of intracranial hematoma. Studies report 20 to $25 \%$ of intracranial brain surgeries for old-aged TBI patients. ${ }^{14,19}$ A single institute study from Newark, United States, reported that 164/823 (20\%) of old-aged patients require brain surgery. ${ }^{19}$ Our study results report that percentage of deaths among old-aged patients $(31 \%)$ who had undergone brain surgery is significantly ( $p=0.001$ ) higher than productive age deaths after surgery (24\%).

The present study reports that old-aged patients had $44 \%$ of moderate to severe injury as per GCS, which is more than productive age group 35\%. Deaths among old-aged population in moderate to severe GCS were more and statistically significant $(p=0.0001)$ than productive age group (-Table 2 ). The old-aged death in our study group is $36 \%$, which is higher than that in productive age group (24\%), which is significant $(p=0.0001)$. The mortality among old-aged trauma varies between 10 and $34 \%{ }^{11,14,20}$ Old-aged population is at risk for greater severity of injury and deaths after $\mathrm{TBI}^{7-10}$ The possible reasons may be anatomical changes such as the dura more adherent to the skull, cerebral atrophy with greater intracranial volumes, and also routine management for associated comorbid conditions. ${ }^{9,10,12,21}$ Increase in old-aged population and greater mortality among old-aged TBI make this group for special attention in management aspects by clinicians and framing preventive measures by stakeholders.

Our study has so few important limitations in data source that no follow-up details are available. The study demonstrates that in-hospital mortality has an adequate measure of outcome. The study is hospital based where population-based study would have been better for generalization. Detailed variables for TBI are limited, but the basic details are provided.

\section{Recommendations}

1. There is need for developing a comprehensive care for providing preventive, curative, and rehabilitation services to the old-aged TBI patients.

2. Specialized geriatric health services should be established for creating awareness among public. Media is a good mode for spreading knowledge and communication programs related to old-aged health issues.

3. CT scans of the head should be compulsorily recommended for all patients aged 60 or older presenting with neurologic symptoms and signs or history of head trauma.

4. Multidepartmental approach is mandate for care of old-aged patients.
5. The financial and human costs of treating TBI in older adults are extensive. Therefore, the government should provide old-age-specific health insurance that covers there treatment charges.

6. Detailed survey on TBIs in old aged in all districts and states of the country should be conducted to obtain national-level data that help in framing safety measures specific to old-aged age group.

In conclusion, our study showed that old-aged population contributes a major part of neurotrauma. Old-aged women and men had almost same percentages of mortality. As compared with productive age group, old-aged patients had significantly higher severity of injury and deaths. There is need to study TBI in old-aged population in greater detail in our country, because of greater expansion of old-aged patients and expected higher TBIs.

\section{References}

1 Shimoda K, Maeda T, Tado M, Yoshino A, Katayama Y, Bullock MR. Outcome and surgical management for geriatric traumatic brain injury: analysis of 888 cases registered in the Japan Neurotrauma Data Bank. World Neurosurg 2014;82(06):13001306

2 Central S. Office. Situation Analysis of the Elderly in India. http:// www.mospi.nic.in/mospi_new/upload/elderly_in_india.pdf. Accessed July 21, 2016

3 India's Elderly Population. Some Fundamentals. March 8, 2013. General Knowledge Today. http://www.gktoday.in/indiaselderly-population-some-fundamentals/. Accessed July 21, 2016

4 Das A, Botticello AL, Wylie GR, Radhakrishnan K. Neurologic disability: a hidden epidemic for India. Neurology 2012;79(21): 2146-2147

5 Broos PL, D'Hoore A, Vanderschot P, Rommens PM, Stappaerts $\mathrm{KH}$. Multiple trauma in elderly patients. Factors influencing outcome: importance of aggressive care. Injury 1993;24(06): 365-368

6 Morris JA Jr, MacKenzie EJ, Damiano AM, Bass SM. Mortality in trauma patients: the interaction between host factors and severity. J Trauma 1990;30(12):1476-1482

7 Qu XD, Shrestha R, Wang MD. Risk factors analysis on traumatic brain injury prognosis. Chin Med Sci J 2011;26(02):98-102

8 Dhandapani S, Manju D, Sharma B, Mahapatra A. Prognostic significance of age in traumatic brain injury. J Neurosci Rural Pract 2012;3(02):131-135

9 Thompson HJ, McCormick WC, Kagan SH. Traumatic brain injury in older adults: epidemiology, outcomes, and future implications. J Am Geriatr Soc 2006;54(10):1590-1595

10 Kehoe A, Smith JE, Bouamra O, Edwards A, Yates D, Lecky F. Older patients with traumatic brain injury present with a higher GCS score than younger patients for a given severity of injury. Emerg Med J 2016;33(06):381-385

11 Akköse Aydin S, Bulut M, Fedakar R, Ozgürer A, Ozdemir F. Trauma in the elderly patients in Bursa. Ulus Travma Acil Cerrahi Derg 2006;12(03):230-234

12 Zeng X, Pan S, Hu Z. Geriatric traumatic brain injury in China. Curr Transl Geriatr Exp Gerontol Rep 2012;1:167-170

13 Coronado VG, Thomas KE, Sattin RW, Johnson RL. The CDC traumatic brain injury surveillance system: characteristics of persons aged 65 years and older hospitalized with a TBI. J Head Trauma Rehabil 2005;20(03):215-228 
14 Munivenkatappa A, Pruthi N, Philip M, Devi BI, Somanna S. Elderly pedestrian neurotrauma: a descriptive study from a premier neurotrauma center in India. J Neurosci Rural Pract 2013;4(01):29-32

15 Munivenkatappa A, Agrawal A, Shukla DP, Kumaraswamy D, Devi BI. Traumatic brain injury: does gender influence outcomes? Int J Crit Illn Inj Sci 2016;6(02):70-73

16 McMillan TM, Teasdale GM. Death rate is increased for at least 7 years after head injury: a prospective study. Brain 2007;130(Pt 10):2520-2527

17 Adam SH, Eid HO, Barss P, et al. Epidemiology of geriatric trauma in United Arab Emirates. Arch Gerontol Geriatr 2008;47(03): $377-382$
18 Dams-O'Connor K, Cuthbert JP, Whyte J, Corrigan JD, Faul M, Harrison-Felix C. Traumatic brain injury among older adults at level I and II trauma centers. J Neurotrauma 2013;30(24): 2001-2013

19 ACEP News. Elderly TBI Patients May Not Benefit from Surgery. By Patrice Wendling. Elsevier Global Medical News April 2011https://www.acep.org/content.aspx?id=79767. Accessed July 28, 2016

20 Day RJ, Vinen J, Hewitt-Falls E. Major trauma outcomes in the elderly. Med J Aust 1994;160(11):675-678

21 Mak $\mathrm{CH}$, Wong SK, Wong GK, et al. Traumatic brain injury in the elderly: is it as bad as we think? Curr Transl Geriatr Exp Gerontol Rep 2012;1(03):171-178 